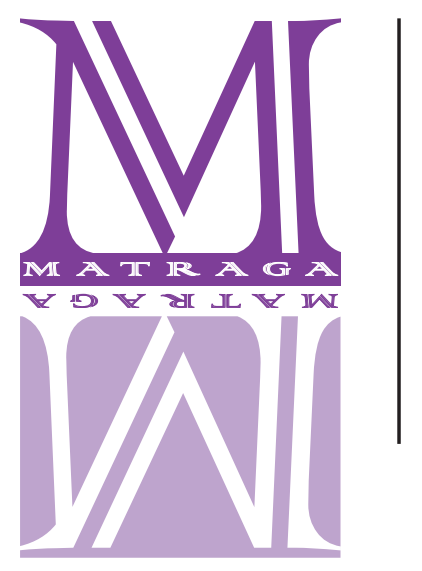

\title{
Os tais caquinhos, de Natércia Pontes
}

\author{
Darlan Roberto dos Santos \\ Faculdade Santa Rita / Faculdade de Direito de Conselheiro Lafaiete, Brasil \\ http://orcid.org/0000-0002-7268-9340
}

\begin{abstract}
A cumulação de afetos, reminiscências, reflexões e objetos. Essa é a realidade de grande parte das pessoas, nas sociedades urbanas de nosso tempo. Acúmulos que consumimos; acúmulos que nos consomem. O sociólogo Zygmunt Bauman chega a afirmar que somos todos consumidores, "primeiro e acima de tudo acumuladores de sensações" (1999, p. 91).

Tintas fortes realçam esse contexto, abordado em Os tais caquinhos, de Natércia Pontes, lançado em 2021 pela editora Companhia das Letras. É difícil definir a obra, que, embora mantenha atributos de um romance, tem a estrutura de um almanaque, repleta de confissões, pequenas narrativas, trechos de diários, relatos de sonhos e detalhadas enumerações. No centro de tamanha miscelânea, a protagonista, Abigail, que revela seu dia a dia e suas angústias, vivenciadas com a irmã mais nova, Berta, e o pai, em um apartamento de classe média. Uma rotina comum, não fosse por um fato: Lúcio, o patriarca, é um acumulador compulsivo:
\end{abstract}

[...] não havia sala. Havia um depósito de caixas de papelão entulhadas de livros que esfarelavam com o tempo. Algumas das caixas tiveram que ocupar a varanda por falta de espaço. Então chovia, e as caixas ficavam encharcadas e depois secavam com o vento e o sol. Passados uns anos, elas viraram um monturo de mofo e de ninho de cupim. A ideia de abrir a porta de vidro com esquadrias enferrujadas era tão apavorante que decidimos não a abrir nunca mais (PONTES, 2021b, n.p).

Aos olhos da psiquiatria, o transtorno de acumulação (TA) é definido como uma dificuldade intransponível de se desfazer de utensílios domésticos, roupas e até lixo. Logo, o acumulador passa a guardar, literalmente, todas as coisas, fazendo de sua própria casa um depósito sem-fim, alimentado diariamente com novas aquisições. Tudo isso parece transbordar em Os tais caquinhos, nos seus 100 pequenos capítulos, distribuídos em 144 páginas (na versão impressa). Como itens da montanha de pensamentos que afligem Abigail, os fragmentos que compõem o livro não obedecem a uma ordem cronológica ou linear; nem mesmo os títulos condizem, necessariamente, com o conteúdo que se segue. É o caos em forma de literatura. O mesmo caos em que vive aquela pequena família. Porém, sempre é possível encontrar um sentido, mesmo na 
anarquia. Há, enfim, significações perceptíveis na trama. Uma delas, mais óbvia, é seu caráter de atualidade - algo recorrente nas produções da autora.

Nascida na cidade de Fortaleza, em 1980, Natércia desponta como uma genuína representante da literatura brasileira contemporânea, tendo publicado outros trabalhos, como Az mulerez (Edição do autor, 2004) e Copacabana dreams (CosacNaify, 2012), com o qual foi finalista do prêmio Jabuti, na categoria crônica/conto. Em ambos, a predileção por histórias curtas, preenchidas de urbanidade e figuras humanas peculiares. São, provavelmente, os traços mais característicos do trabalho da escritora, ao explorar as múltiplas facetas do sujeito pós-moderno, quase sempre, impregnado de neuroses e compulsões. Essa é também uma das vertentes da literatura no século XXI:

[...] como testemunha do individualismo contemporâneo, o eu e as suas experiências, mesmo minúsculas, têm sido privilegiados; o ceticismo aumentou, chegando até o niilismo, a impossibilidade de um grande relato histórico, no qual situar as vivências contemporâneas, acarretou o desaparecimento da literatura de mensagens políticas explícitas, limitando a obra de ficção à denúncia de um real insatisfatório ou mesmo catastrófico; a significação política das obras tornou-se assim ainda mais aberta, ou suspensa; acentuou-se o uso de imagens interagindo com o texto (PERRONE-MOISÉS, 2016, p. 46).

Os tais caquinhos insere-se em tal tendência da literatura de nossa época, ao constituir-se em um mosaico de pequenos atos cotidianos, mesclados a elucubrações da narradora, imersa na bagunça de seu apartamento e na ilusão de que, fora dali, possa existir alguma harmonia:

Lá fora tudo parecia estar em ordem. Lá dentro a louça era desencontrada, assim como os trapos de cama e de banho. Lá dentro os quadros estavam sempre por ser pendurados e as panelas exibiam depressões, nódoas pretas, tampas avulsas e cabos soltos. Havia uma camada de gordura na superfície dos poucos móveis de que dispúnhamos. E a ausência de sofá me envergonhava fundo (PONTES, 2021b, n.p).

Não há ocorrências especialmente memoráveis, mas existe um universo particular a ser desvelado. Ao situar o enredo na década de 1990, a autora parece nos mostrar que, mesmo em uma geração anterior (ainda sem o fascínio das redes sociais e a dependência generalizada do smartphone), as implicações da vida de uma jovem não diferem significativamente daquelas da geração atual. Assim, as partículas que compõem o texto vão encadeando-se, de modo a nos revelar a relação de carinho que Abigail tem com o pai acumulador, os porquês de sua mãe ter deixado o lar, suas paixões, amizades e referências absorvidas da cultura pop.

Aliás, o título Os tais caquinhos é uma menção explícita à canção Pra começar, que fez parte do álbum Todas Ao Vivo, lançado originalmente em 1986 por Marina Lima, artista brasileira em evidência no momento retratado na obra. A música foi escrita pelo poeta Antônio Cícero, em parceria com a cantora, que é sua irmã - a mesma artista que criou os versos: "Eu espero um acontecimento. Só que, quando anoitece, é festa no outro apartamento...” (LIMA, 1991).

Marina, Natércia e tantos outros atentos observadores de seu tempo, desvendando "arquiteturas idealizadoras de distopias espaciais, quando as verticalidades e horizontalidades, os aber- 
tos e os fechados, os espelhos e os concretos das ruas e dos asfaltos, perfazem novos sentidos de significação da vida moderna em grandes cidades” (COSTA, 2020, p. 34).

Afora o teor cronístico, "Os tais caquinhos é um romance de formação ou quase" (PONTES, 2021a, n.p), conforme atesta a própria autora. Ao assumir o gênero (conceitualmente definido como Bildungsroman), Natércia Pontes acena para a - sempre possível - conciliação entre as novas tendências literárias e o terreno já sedimentado na arte de contar histórias e representar o real. No caso em questão, trata-se de obras que, a partir do século XVIII, passaram a enfatizar a formação da burguesia, na figura de jovens protagonistas, em narrativas que percorrem o desenvolvimento de sua personalidade e a inserção na esfera social. O "quase" fica por conta da maneira desconcertante e pouco usual escolhida pela escritora, ao lançar luz sobre a existência - e o obscuro apartamento - de Abigail:

Da rua, os faróis dos carros rareavam vez ou outra iluminando com uma intensidade débil os tubos de papelão ocos, os arquivos mortos, escaninhos vazios, revisteiros empilhados, cupons fiscais de farmácia, tampas de caixas soltas, refis de canetas secos e mais uma variedade de objetos pardos e cobertos de poeira. [...] A luz passageira de um carro acariciava meu rosto, me despertando do transe. Então esquecia que vivia no apartamento mais sujo do mundo e ia dormir em paz (PONTES, 2021b, n.p).

No emaranhado discursivo, composto de episódios corriqueiros, excertos de bilhetes, passagens oníricas e descrições minuciosas (algumas escatológicas), a coesão, definitivamente, não é primordial. Talvez, por isso, o formato E-Book (no qual se baseou esta resenha) intensifique a fruição da obra, ampliando a sensação de que a vida daquela família é regida pela mais completa imprevisibilidade, sem demarcações. É o que a leitura no aplicativo Kindle proporciona. Emulando o concreto, dispensando estruturas rígidas, a publicação digital oferece configurações variáveis, paginações irregulares. Afinal, para que ordenar capítulos? Por que numerar páginas? Lúcio e as filhas desconhecem a organização. Não há critérios; nem mesmo, coerência.

Paradoxalmente (como se pode esperar de um livro que retrata a contemporaneidade), a jovem Abigail vislumbra algum sentido no caos:

É MUITO BOM SENTIR FOME. Talvez a maior das lições de Lúcio. A segunda é que cultivássemos o pensamento livre, sem muitas certezas. Embora entendesse de uma maneira intuitiva e nada palpável o que Lúcio queria nos dizer com isso, eu me acostumei a exercitar a dúvida acerca de tudo (PONTES, 2021b, n.p).

Esse é o mundo de Abigail. Esse é o nosso mundo em cacos.

\section{REFERÊNCIAS}

BAUMAN, Zygmunt. Globalização: as consequências humanas. Tradução por Marcus Penchel. Rio de Janeiro: Zahar, 1999. 
COSTA, Wendell Marcel Alves da. Crônicas urbanas, espaços de solidão e afetos desestabilizados no cinema latino-americano. Caderno eletrônico de Ciências Sociais, v. 8, s.n., p. 31-59, 2020.

LIMA, Marina. Todas Ao Vivo. Direção artística de Sérgio Luiz e Antônio Cícero. Rio de Janeiro: Philips Records, 1986. 1 disco (44 min), son.

LIMA, Marina. Marina Lima. Direção artística de Liminha e Fábio Fonseca. Rio de Janeiro: Emi-Odeon, 1991. 1 disco (41 min), son.

PERRONE-MOISÉS, Leyla. Mutações da literatura no século XXI. São Paulo: Companhia das Letras, 2016.

PONTES, Natércia. Os tais caquinhos: em processo. 2021a. Disponível em: <https://blogdoims.com.br/os-tais-caquinhos/>. Acesso em: 21 mar. 2021.

PONTES, Natércia. Os tais caquinhos. São Paulo: Companhia das Letras, $2021 b$. 